\title{
Effect of verbal persuasion on self-efficacy for pain-related diagnostic sensory testing in individuals with chronic neck pain and healthy controls - a randomized, controlled trial
}

\author{
This article was published in the following Dove Press journal: \\ Journal of Pain Research \\ 7 March 2016 \\ Number of times this article has been viewed
}

\author{
Anne Söderlund' \\ Michele Sterling ${ }^{2}$ \\ 'Physiotherapy, School of Health, \\ Care and Social Welfare, Mälardalen \\ University, Västerås, Sweden; \\ ${ }^{2}$ Centre for National Research on \\ Disability and Rehabilitation Medicine \\ (CONROD), Menzies Health Institute \\ Queensland, Griffith University, \\ Parklands, Australia
}

\begin{abstract}
The aim of this study was to investigate the differences in cold pain threshold (CTh), pressure pain threshold (PPT), cold pain tolerance (CPTo) tests, and the level of self-efficacy when self-efficacy for diagnostic sensory testing was manipulated by verbal persuasion before a testing situation in persons with neck pain and in healthy controls. A randomized experimental design was used. Twenty-one healthy volunteers and 22 individuals with either traumatic or nontraumatic chronic neck pain were recruited to participate in the study. The intervention consisted of two experimental verbal persuasion conditions: Increase self-efficacy and Decrease self-efficacy. The PPT was measured using a pressure algometer, the CTh was measured using a thermo test system, and CPTo was measured by submerging the participant's hand in ice water up to the elbow joint. On three occasions, the participants reported their self-efficacy level in performing the sensory tests. In the chronic neck pain group, there were no differences in pain threshold or tolerance. There was a difference in the self-efficacy level after verbal persuasion between the experimental conditions. In the healthy control group, the CThs increased following the condition that aimed to increase self-efficacy. No other differences were observed in the healthy controls. A short verbal persuasion in the form of manipulative instructions seems to have a marginal effect on the individual's self-efficacy levels in the chronic neck pain group and a slight influence on the results of sensory testing in healthy controls.
\end{abstract}

Keywords: pressure pain threshold, cold pain threshold, cold pain tolerance, self-efficacy, randomized trial

\section{Introduction}

Twenty-two percent of persons with whiplash-associated disorders (WAD) show early signs of hypersensitivity persisting over time. ${ }^{1}$ Sensory hypersensitivity measured using pressure and cold pain thresholds (CThs) was related to persistent moderate or severe symptoms in patients with $\mathrm{WAD}^{2}$ and poor recovery after neck trauma. ${ }^{2}$ Additionally, patients with chronic neck pain without any trauma have been shown to have a decreased pressure pain threshold (PPT) in the cervical area, ${ }^{3}$ over the trapezius, ${ }^{4}$ and in the trigeminal region. ${ }^{5}$ Thus, patients with or without trauma seeking health care are often exposed to diagnostic sensory testing to better understand their painrelated problems.

Psychological factors could influence the results of sensory hypersensitivity tests. Rhudy and Meagher ${ }^{6}$ reported that pain tolerance was influenced by fear and anxiety. Studies on patients with WAD have shown an association between catastrophizing, cc) the work you hereby accept the Terms. Non-commercial uses of the work are permitted without any further permission from Dove Medical Press Limited, provided the work is properly attributed. For permission for commercial use of this work, please see paragraphs 4.2 and 5 of our Terms (https://www.dovepress.com/terms.php). 
ie, a set of irrationally negative cognitive and emotional responses on actual or anticipated painful stimuli, ${ }^{7}$ and the CTh. ${ }^{8}$ Additionally, patients with osteoarthritis who reported high self-efficacy in coping with pain showed a higher experimental pain tolerance and threshold compared to those with low self-efficacy. ${ }^{9}$ Self-efficacy beliefs are defined as a person's conviction to successfully perform a required behavior or activity. ${ }^{10}$

Dolce et $\mathrm{al}^{11}$ reported a strong correlation between experimental acute pain tolerance and self-efficacy ratings. They concluded that self-efficacy expectancies are a better predictor of pain tolerance than pain intensity ratings. It could be hypothesized that verbal persuasion related to self-efficacy before diagnostic painful sensory testing could have an impact on the test results. According to Bandura, ${ }^{10}$ verbal persuasion is one approach to increase self-efficacy. However, recent experimental studies of self-efficacy in painful diagnostic sensory testing are lacking. Because verbal persuasion influences self-efficacy, it is likely that different types of instructions conveyed to the patient from the health care staff in diagnostic sensory testing might influence the results of the sensory tests. Furthermore, there are no studies comparing the effects of sensory testing after verbal persuasion on the self-efficacy of individuals with chronic neck pain and those of healthy people. The pain itself could probably affect the perceived self-efficacy for testing, and individuals with pain could also be more sensitive to verbal persuasion related to self-efficacy compared to persons without pain.

Therefore, the aim of this study was to investigate 1) the differences in CTh, PPT, and cold pain tolerance (CPTo), 2 ) the level of self-efficacy when self-efficacy for diagnostic sensory testing is manipulated before a testing situation, and 3) whether persuasion increases or decreases selfefficacy in persons with neck pain and in healthy controls. Furthermore, the aim was to study whether there are any differences in the self-efficacy responses for sensory tests between individuals with chronic neck pain and healthy controls. We also aimed to study if there are any changes in the level of self-efficacy over time from the period before the persuasion to the periods after the persuasion and after the sensory tests.

\section{Materials and methods}

\section{Ethics statement}

The study was approved by the Medical Research Ethics Committee, The University of Queensland. All of the participants provided their written informed consent.
After completing the study, the participants were debriefed regarding the aims and nature of the study.

\section{Design}

A randomized experimental design was used. The two samples - healthy controls and individuals with chronic neck pain - were separately randomized to two different experimental conditions with pre-, during, and postintervention measures (Figure 1).

\section{Participants}

The main inclusion criterion was that the participants had not previously participated in sensory testing. A convenience sample of 21 healthy volunteers, 18-65 years of age, was recruited from among the employees (current or previous) of University of Queensland, Australia. The healthy controls were included if they had experienced no pain that required treatment in the previous 12 months.

Twenty-two individuals, 18-65 years of age with either traumatic or nontraumatic chronic neck pain ( $>3$ months), were consecutively recruited from a research database of individuals who had previously volunteered for research studies in Queensland, Australia. The exclusion criteria were any other relevant medical conditions, such as neurological or rheumatological diseases, and diagnoses of any psychiatric condition.

\section{Study procedure}

The experimental procedure was standardized in a written protocol. The three sensory tests were conducted in the same order for each participant. The detailed procedure is presented in Figure 1.

\section{Randomization and interventions}

The healthy controls and individuals with chronic neck pain were separately randomized, via a computer-generated randomization list, to one of two experimental conditions.

Intervention was based on Bandura's ${ }^{10}$ theory of selfefficacy. The two experimental conditions included the following sentences:

- Increase self-efficacy: "I know you can manage to do this test very well. Others have experienced no problems with these tests. I know and I'm sure that people around you think that you are a 'tough' person and will have no problems handling the test situation."

- Decrease self-efficacy: "I know this is going to be hard for you and it is not going to be easy for you to complete the tests. Others have experienced these tests to be painful and difficult to complete." 


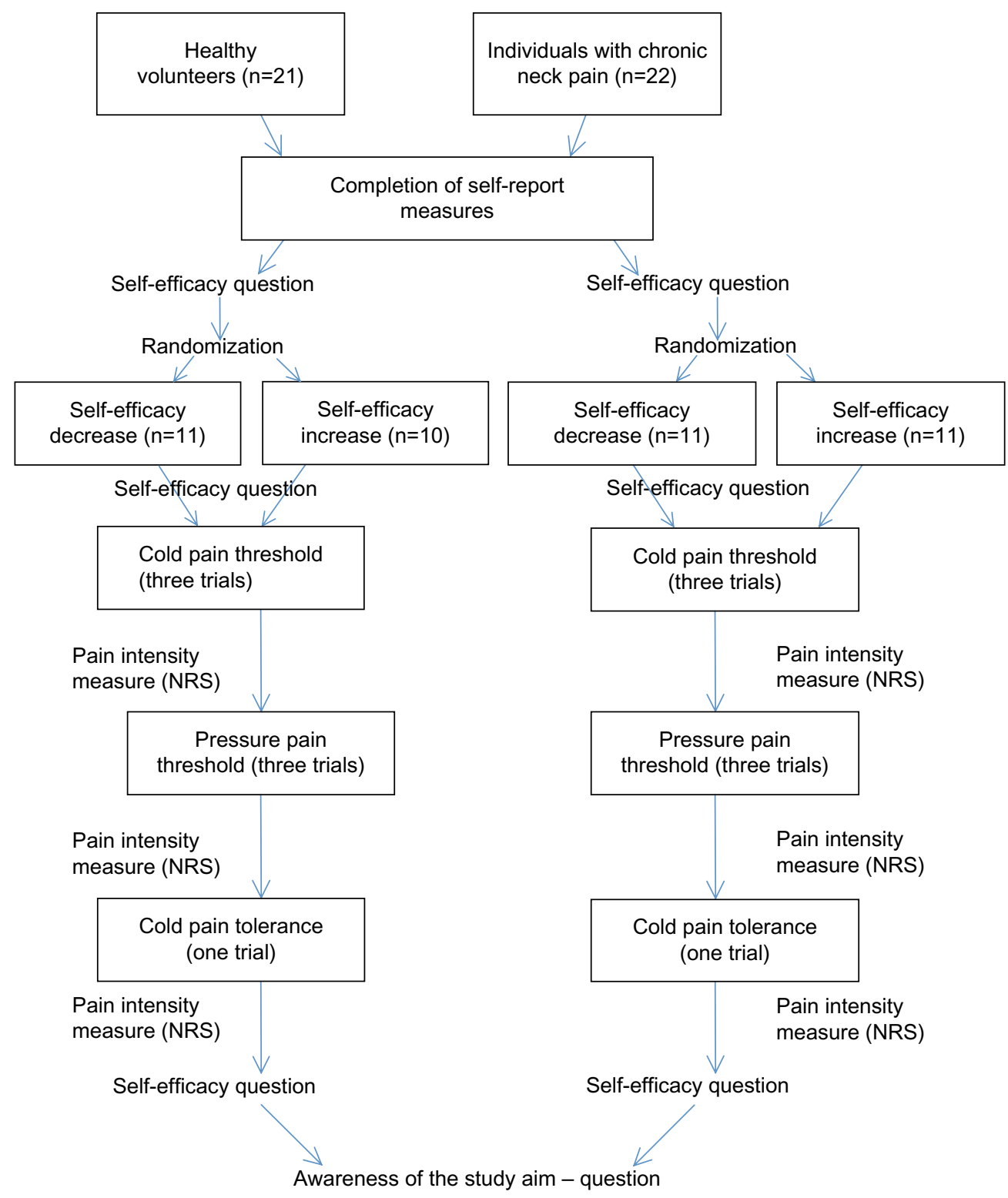

Figure I The study design and procedure. Abbreviation: NRS, numeric rating scale.

\section{Measures}

PPT was measured using a pressure algometer with a probe size of $1 \mathrm{~cm}^{2}$. PPT was measured on the spinous process of the fifth cervical vertebra (C5). ${ }^{8}$

$\mathrm{CTh}$ was measured over the mid-cervical spine using the MSA Thermotest system (Somedic AB, Farsta, Sweden). A thermode was placed between $\mathrm{C} 2$ and $\mathrm{C} 5 .{ }^{8}$ For safety reasons, the temperature was not decreased to $<8^{\circ} \mathrm{C}$.

CPTo was measured by submerging the participant's hand in ice water up to the elbow joint with the fingertips in contact with the bottom of the tank. CPTo was measured according to the number of seconds the participant could maintain his/her hand in the water with the fingertips touching the bottom. ${ }^{11}$
For the PPT and CTh tests, the mean values for the three trials were used in all of the analyses.

\section{Self-reported measures}

Self-efficacy is situation dependent; therefore, a studyspecific measure was used. ${ }^{10}$ After informing the participants about the three sensory tests, they were asked the question: "How confident are you in your ability to perform the three sensory tests?" A Numeric Rating Scale, ranging from 0 to 10 - where 0 indicated not at all confident and 10 indicated very confident, was used. Self-efficacy was measured three times due to its characteristics of being variable from one situation to 
another: before persuasion, after persuasion but before testing, and after all sensory tests.

The following measures were completed at baseline:

The Pain Catastrophizing Scale (PCS), ${ }^{7}$ which is a reliable and valid measure, was used to explore catastrophizing thoughts. A total score ranged between 0 and 52 .

The Neck Disability Index (NDI) ${ }^{12}$ measures disability varying from 0 to 50 (full disability). The NDI demonstrates moderate-to-strong evidence of reliability and different types of validity. ${ }^{13}$

One subscale from the 36-Item Short Form Health Survey $(\mathrm{SF}-36)^{14}$ was used to measure mental health. A higher score (in percentage) indicated better health. The SF-36 is a reliable and valid measure. ${ }^{14,15}$

The general health measure consisted of one item developed for this study: "In general, would you say your health is...?" A five-grade ordinal scale from "Excellent $(=1)$ " to "Poor (=5)" was used.

Average pain intensity during the past week was measured using a Numeric Rating Scale ranging from 0 to 10, where 0 indicated no pain and 10 indicated maximal imaginable pain. ${ }^{16}$

To control the blinded participants' awareness of the aims of the study, the participants were asked after the experiment to express in their own words what they thought was the aim(s) of the experiment. If they expressed that they could notice a relationship between their own self-efficacy reports and the experimenter's persuasive "talk," they were classified as "aware"; otherwise, they were classified as "unaware". ${ }^{17}$

\section{Statistical analyses}

Independent $t$-tests, Mann-Whitney $U$-test, and chi-square test were used when analyzing differences between the two groups. Wilcoxon's test was used to analyze changes over time. Because catastrophizing may influence the results of sensory testing, ${ }^{8}$ we analyzed the differences among the participants in each of the experimental conditions. There were no differences between any of the groups; thus, pain catastrophizing was not included as a covariate in further analyses.

Parametric analyses were conducted using Bootstrapping, Simple Form, with 1,000 samplings. Bootstrapping was used to control the stability of the results. ${ }^{18}$ The results of the analyses with or without Bootstrapping were similar. Thus, the reported results are from non-Bootstrap analyses. The level of statistical significance was set at $P<0.05$.

\section{Sample size reasoning}

This study was explorative in nature due to the nonexistent knowledge of the outcome of studies on the effects of verbal persuasion on individuals' self-efficacy during sensory testing. In one experimental study, ${ }^{19}$ ten participants were included in each of the five groups. The author of that study showed that self-efficacy in enduring a cold pressure test was a significant predictor for changes in cold pressure tolerance tests when manipulating self-efficacy. On the basis of that study, we decided that a sample size of 10-11 individuals in each group could be sufficient to detect group differences in the sensory tests after verbal persuasion related to self-efficacy.

\section{Results}

There were 14 females and seven males, with mean age of 36 years (standard deviation $[\mathrm{SD}]=11.6$ years) in the healthy control group. Twelve of the 21 individuals were employed and nine individuals reported "Home duties" as their current working status. In the chronic neck pain group, there were eight individuals (all females) with neck pain without any neck trauma and 14 ( $\mathrm{n}=8$ females, 6 males) who had whiplash-trauma-related neck pain. The neck pain participants with or without neck trauma did not differ from each other in age, working status, education, number of pain medications, number of pain areas in the whole body, pain intensity during past week, pain catastrophizing, or general health. Their mean age was 46 years $(\mathrm{SD}=11.9)$; 14 were employed, two were self-employed, one reported Home duties as working status, and four were unemployed. Eighteen of the 22 individuals with chronic neck pain used pain medication, such as paracetamol or a similar agent.

There was a significant baseline difference in age between the healthy controls and individuals with chronic neck pain. The healthy control group was younger. There was also a significant baseline difference in general health between individuals with chronic neck pain and healthy controls ( $P=0.006$ ), with the neck pain group reporting worse general health. There were no other significant differences at baseline. The healthy controls did not use any pain medication. The descriptive statistics for the participants with chronic neck pain and healthy controls are shown in Table 1.

\section{Differences in sensory test results and levels of self-efficacy between the experimental conditions in individuals with chronic neck pain}

In the chronic neck pain group, there were no significant differences in the sensory test results between the two experimental conditions Increase self-efficacy and Decrease self-efficacy (Table 2). No significant differences were found in pain intensity before and after each test between the 
Table I Descriptive statistics before sensory testing for individuals with chronic neck pain and healthy controls respectively

\begin{tabular}{lll}
\hline Measures & $\begin{array}{l}\text { Individuals with } \\
\text { chronic neck pain, } \\
\text { mean (SD), n=22 }\end{array}$ & $\begin{array}{l}\text { Healthy } \\
\text { controls, mean } \\
\text { (SD), n=2 I }\end{array}$ \\
\hline $\begin{array}{l}\text { Self-efficacy during sensory } \\
\text { testing, before manipulation }\end{array}$ & $8.5(\mathrm{I} .6)$ & $8.5(\mathrm{I} .6)$ \\
General health* & $2.9(0.9)$ & $2.1(0.8)$ \\
SF-36 mental health & $68(15.5)$ & $69.7(9.3)$ \\
Pain catastrophizing & $14.2(9.5)$ & $12.3(8.0)$ \\
Neck Disability Index & $16.5(8.4)$ & $\mathrm{NA}$ \\
Pain intensity in previous week $5.8(2.4)$ & 0 \\
\hline
\end{tabular}

Note: *significant difference between the groups.

Abbreviations: NA, not applicable; SD, standard deviation; SF-36, 36-Item Short Form Health Survey.

experimental conditions Increase self-efficacy and Decrease self-efficacy (Table 2).

In the chronic neck pain group, there was no significant difference in self-efficacy before manipulation between the experimental conditions Increase self-efficacy and Decrease self-efficacy. The difference between the experimental conditions in the self-efficacy levels after the manipulation but before the tests was significant $(P=0.045)$, and after the sensory tests, the difference approached significance $(P=0.067)$. Table 3 shows the mean and SD values.

\section{Differences in sensory test results and levels of self-efficacy between the experimental conditions in healthy controls}

In the healthy control group, there was a significant difference in the CTh between the experimental conditions Increase

Table 2 Mean, SD and P-values for the sensory tests and pain intensity in the experimental conditions "Increase self-efficacy" and "Decrease self-efficacy" for the individuals with chronic neck pain

\begin{tabular}{|c|c|c|c|}
\hline $\begin{array}{l}\text { Individuals with } \\
\text { chronic neck pain } \\
\text { measures }\end{array}$ & $\begin{array}{l}\text { Decrease } \\
\text { self-efficacy, } \\
\text { mean (SD), } \\
n=\mid \text { I }\end{array}$ & $\begin{array}{l}\text { Increase } \\
\text { self-efficacy, } \\
\text { mean (SD), } \\
\mathrm{n}=\text { I I }\end{array}$ & $P$-value \\
\hline $\begin{array}{l}\text { Cold pain threshold on } \\
\mathrm{C} 2-\mathrm{C} 5,{ }^{\circ} \mathrm{C}\end{array}$ & $13.0(7.1)$ & $10.6(3.6)$ & 0.34 \\
\hline \multicolumn{4}{|l|}{ Pain intensity } \\
\hline Before test & $3.8(2.2)$ & $3.1(2.1)$ & 0.44 \\
\hline After test & $3.9(2.8)$ & $3.6(2.1)$ & 0.74 \\
\hline $\begin{array}{l}\text { Pressure pain threshold } \\
\text { on } \mathrm{C} 5, \mathrm{kPa} / \mathrm{s}\end{array}$ & $365.8(124.1)$ & $341.8(80.8)$ & 0.60 \\
\hline Pain intensity, after test & $3.8(2.8)$ & $3.5(2.3)$ & 0.74 \\
\hline $\begin{array}{l}\text { Cold pain tolerance, } \\
\text { seconds }\end{array}$ & $35.2(68.4)$ & $61.9(77.4)$ & 0.40 \\
\hline Pain intensity, after test & $3.9(2.9)$ & $3.1(2.2)$ & 0.46 \\
\hline
\end{tabular}

Abbreviations: SD, standard deviation; $C 2$, second cervical vertebra; $C 5$, fifth cervical vertebra.
Table 3 Mean and SD in self-efficacy at the three time points for the individuals with chronic neck pain and healthy controls separately in both experimental conditions

\begin{tabular}{|c|c|c|c|c|}
\hline \multirow[t]{2}{*}{ Measures } & \multicolumn{2}{|c|}{ Increase self-efficacy } & \multicolumn{2}{|c|}{ Decrease self-efficacy } \\
\hline & $\begin{array}{l}\text { Individuals } \\
\text { with chronic } \\
\text { neck pain, } \\
\text { mean (SD), } \\
\text { n=I I }\end{array}$ & $\begin{array}{l}\text { Healthy } \\
\text { controls, } \\
\text { mean } \\
(\mathrm{SD}), \\
\mathrm{n}=10\end{array}$ & $\begin{array}{l}\text { Individuals } \\
\text { with chronic } \\
\text { neck pain, } \\
\text { mean (SD), } \\
\text { n=I I }\end{array}$ & $\begin{array}{l}\text { Healthy } \\
\text { controls, } \\
\text { mean } \\
(\mathrm{SD}), \\
\mathrm{n}=10\end{array}$ \\
\hline $\begin{array}{l}\text { Self-efficacy } \\
\text { before } \\
\text { manipulation }\end{array}$ & $8.9(1.4)$ & $9.0(1.2)$ & $8.0(1.8)$ & $8.1(1.9)$ \\
\hline $\begin{array}{l}\text { Self-efficacy } \\
\text { after } \\
\text { manipulation, } \\
\text { before tests }\end{array}$ & $9.2(1.1)$ & $8.9(1.2)$ & $7.9(1.7)$ & $8.3(1.7)$ \\
\hline $\begin{array}{l}\text { Self-efficacy } \\
\text { after sensory } \\
\text { tests }\end{array}$ & $10.0(0)$ & $9.9(0.3)$ & $9.5(0.9)$ & $9.7(0.7)$ \\
\hline
\end{tabular}

Abbreviation: SD, standard deviation.

self-efficacy and Decrease self-efficacy. The mean CTh of the Increase self-efficacy group was lower than that of the Decrease self-efficacy group. The results for sensory tests in terms of the mean, $\mathrm{SD}$, and $P$-values are presented in Table 4 . The healthy controls rated zero in pain intensity both before and after each test.

There were no differences between the conditions Increase self-efficacy and Decrease self-efficacy in the selfefficacy levels for healthy controls at any time point. Table 3 lists the mean and $\mathrm{SD}$ values.

\section{Differences in self-efficacy between} individuals with chronic neck pain and healthy controls per experimental condition

There were no significant differences between the individuals with chronic neck pain and the healthy controls in terms of self-efficacy at any time point in either the Increase selfefficacy or the Decrease self-efficacy experimental condition. The mean and SD values for self-efficacy in the individuals with chronic neck pain and the healthy controls separately in both experimental conditions are presented in Table 3 .

\section{Changes in self-efficacy levels over time within each experimental condition in individuals with chronic neck pain and healthy controls}

There was a significant increase in self-efficacy over time from the time before manipulation to time after testing 
Table 4 Mean, SD and $P$-values of the sensory tests for the experimental conditions "Increase self-efficacy" and "Decrease self-efficacy" for the healthy controls

\begin{tabular}{llll}
\hline $\begin{array}{l}\text { Healthy controls } \\
\text { Measures }\end{array}$ & $\begin{array}{l}\text { Decrease } \\
\text { self-efficacy, } \\
\text { mean (SD), } \\
\text { n=I I }\end{array}$ & $\begin{array}{l}\text { Increase } \\
\text { self-efficacy, } \\
\text { mean (SD), } \\
\mathbf{n}=10\end{array}$ & P-value \\
\hline $\begin{array}{l}\text { Cold pain threshold } \\
\text { on C2-C5, }{ }^{\circ} \mathrm{C}\end{array}$ & II.I (3.7) & $8.3(\mathrm{I} . \mathrm{I})$ & 0.04 \\
$\begin{array}{l}\text { Pressure pain } \\
\text { threshold on C5, kPa/s }\end{array}$ & $386.8(130.0)$ & $501.2(152.7)$ & 0.08 \\
$\begin{array}{l}\text { Cold pain tolerance, } \\
\text { seconds }\end{array}$ & $50.2(75.6)$ & $48.0(70.5)$ & 0.95 \\
\hline
\end{tabular}

Abbreviations: SD, standard deviation; C2, second cervical vertebra; C5, fifth cervical vertebra.

( $P=0.03$ ), as well as from the time after manipulation but before testing to time after sensory tests $(P=0.03)$ for the Increase self-efficacy condition in the individuals with chronic neck pain. No significant difference in self-efficacy was found between before manipulation and after manipulation but before testing stages.

There was a significant increase in self-efficacy over time from time before manipulation to time after testing $(P=0.04)$, as well as from time after manipulation but before testing to after sensory tests $(P=0.02)$ for the Decrease self-efficacy condition in the individuals with chronic neck pain. No significant difference in self-efficacy was found between before manipulation and after manipulation but before testing stages.

There was a significant increase in self-efficacy over time from before manipulation to after testing $(P=0.02)$ and after manipulation but before testing to after sensory tests $(P=0.02)$ for the Increase self-efficacy condition in the healthy controls. No significant difference in self-efficacy was found between before manipulation and after manipulation but before testing stages.

There was a significant increase in self-efficacy over time from before manipulation to after testing $(P=0.01)$ and after manipulation but before testing to after sensory tests $(P=0.009)$ for the Decrease self-efficacy condition in the healthy controls. No significant difference in self-efficacy was found between before manipulation and after manipulation but before testing stages. Table 3 presents the mean and $\mathrm{SD}$ values.

None of the 43 participants was aware of the aim(s) of the experiment or the relationships between the variables investigated in the study.

\section{Discussion}

In the chronic neck pain group, there were no differences in pain threshold or tolerance between the experimental conditions. In contrast, in the healthy control group, the CThs increased (ie, pain was perceived at a lower temperature) following the condition that aimed to increase self-efficacy. There was a significant difference in the self-efficacy levels directly after the verbal persuasion between the experimental conditions Increase self-efficacy and Decrease self-efficacy for the patients with chronic neck pain. Those who had Decrease self-efficacy manipulation scored lower in their self-efficacy for sensory testing before the testing situation commenced compared to those in the Increase self-efficacy group. Furthermore, the results showed that there were no differences in self-efficacy at any time points between the individuals with neck pain and the healthy controls when they were compared separately in the respective experimental conditions. Thus, all of the participants were equally sensitive (or nonsensitive) to verbal persuasion. However, the results within increasing and decreasing manipulation conditions for both healthy controls and individuals with neck pain separately showed an increase over time in self-efficacy from before sensory testing to after testing.

Previous research has shown associations between psychological factors and sensory hypersensitivity in patients with neck pain. ${ }^{8,9}$ This finding could imply that patients with neck pain could be sensitive to psychological manipulation in a diagnostic sensory testing situation. Our study failed to support this hypothesis, showing only one difference in sensory tests between the experimental conditions, and that in the healthy controls. Putting together the earlier studies and our results, the possibility that the instructions given before diagnostic sensory testing might have an impact on the sensory test results cannot be fully eliminated.

The results showed higher self-efficacy levels in the patients with chronic neck pain who belonged to the Increase self-efficacy manipulation group compared to those in the Decrease self-efficacy group directly after the verbal persuasion but before the tests. de Jong et $\mathrm{al}^{20}$ concluded in their study on healthy volunteers that verbal persuasion was not enough to evoke placebo-induced pain reduction. Additionally, Ashford et al, ${ }^{21}$ in a recent meta-analysis of ways to change self-efficacy when promoting lifestyle and physical activity, showed that verbal persuasion was associated with lower levels of self-efficacy. Lee et $\mathrm{al}^{22}$ stated that a short instruction affected sensory threshold responses. Thus, there are mixed results on whether verbal persuasion might play 
a role in an individual's self-efficacy levels. Future studies should investigate this issue.

Both healthy controls and individuals with neck pain increased their self-efficacy over time after the tests. Mastering an experience might have a better effect on an individual's self-efficacy levels compared to short verbal persuasion. The experience of coping well during the tests might have been a strong trigger to increase one's self-efficacy despite the direction of the manipulation the individual received before the tests.

According to Bandura, ${ }^{10}$ self-efficacy beliefs seem to regulate human functioning through four processes, ie, cognitive, motivational, affective, and selective processes. These different processes usually operate together, rather than in isolation, in the regulation of human functioning. ${ }^{10}$ Thus, irrespective of the marginal results of self-efficacy manipulation on diagnostic sensory testing, the complexity of an individual's regulation of functioning suggests that health care staff should consider the neutrality of the content and how the instructions in a clinical sensory testing situation are given.

Bandura ${ }^{10}$ has claimed that self-efficacy expectancies are the most relevant issues in pain management. Self-efficacy beliefs have been reported as being related to functional capacity $^{23}$, pain-related disability ${ }^{24}$, and coping with pain. ${ }^{25}$ These earlier findings suggest that self-efficacy beliefs are useful predictors of disability and pain intensity. Additionally, in this study, the changes in self-efficacy levels over time might indicate that health care staff should consider the perceived impact of experiences during sensory testing situations and in other types of medical examinations. The experiences in testing and examination situations could affect a patient's self-efficacy both negatively and positively, which in turn might be generalized to other similar medical examinations and possibly evoke fear or distrust of health care. However, this observation requires further investigation.

Several limitations of this study need to be mentioned. A primary limitation in our study may have been the short verbal manipulative intervention. There may have been different results if the dialogue with the participants was increased. However, Lee et $\mathrm{al}^{22}$ used a short instruction (only one sentence) in their study of interaction between active and passive coping and perceived intensity of acupuncture intervention. The authors concluded that the given instructions could affect therapeutic outcomes and sensory threshold responses. Additionally, we wanted to maintain a test situation that was similar to the testing situations in clinical practice where lack of time often limits the small talk before testing.
The self-efficacy level for sensory testing was high in both the healthy and the neck pain groups before the persuasion. Thus, the occurrence of ceiling effect is a possibility. We used a one-item measure (even though based on Bandura's recommendations ${ }^{10}$ ) that had not been psychometrically tested, which may have contributed to the high self-efficacy scores initially.

Our sample of individuals with neck pain was combined, consisting of those with or without whiplash-related trauma. The possible heterogeneity could be one reason for the nonsignificant differences between the experimental conditions and between the healthy controls and the individuals with chronic neck pain. However, the participants with WAD did not differ in terms of relevant demographic variables from those without trauma.

One explanation for the lack of expected differences could be type II error, ie, the effect of the small sample size. The within-sample variation in the sensory test results could have been smaller if the sample size were larger, thus resulting in significant differences between the experimental conditions. Regarding generalizability, our sample with chronic neck pain was similar to those in previous studies regarding age, ${ }^{26}$ pain intensity, ${ }^{26}$ and NDI scores. ${ }^{8}$

\section{Conclusion}

On a subjective level, the participants responded, in part, to self-efficacy manipulation as expected, but not on a physiological level. A short persuasion on increasing or decreasing self-efficacy in sensory tests had only a marginal effect on the sensory test results of the healthy controls and an effect on the self-efficacy levels for the individuals with chronic neck pain. All of the participants, independent of the direction of manipulation, increased their self-efficacy over time. Health care staff should be aware of the potential importance of maintaining neutrality in the instructions and the patients' experiences in a sensory testing situation.

\section{Disclosure}

The authors report no conflicts of interest in this work.

\section{References}

1. Sterling M, Jull G, Vicenzino B, Kenardy J. Sensory hypersensitivity occurs soon after whiplash injury and is associated with poor recovery. Pain. 2003;104(3):509-517.

2. Sterling M. Differential development of sensory hypersensitivity and a measure of spinal cord hyperexcitability following whiplash injury. Pain 2010;150(3):501-506. 
3. Javanshir K, Ortega-Santiago R, Mohseni-Bandpei MA, MiangolarraPage JC, Fernandez-de-Las-Penas C. Exploration of somatosensory impairments in subjects with mechanical idiopathic neck pain: a preliminary study. J Manipulative Physiol Ther. 2010;33(7):493-499.

4. Sjors A, Larsson B, Persson AL, Gerdle B. An increased response to experimental muscle pain is related to psychological status in women with chronic non-traumatic neck-shoulder pain. BMC Musculoskelet Disord. 2011;12:230.

5. La Touche R, Fernandez-de-Las-Penas C, Fernandez-Carnero J, DiazParreno S, Paris-Alemany A, Arendt-Nielsen L. Bilateral mechanicalpain sensitivity over the trigeminal region in patients with chronic mechanical neck pain. J Pain. 2010;11(3):256-263.

6. Rhudy J, Meagher M. Fear and anxiety: divergent effects on human pain thresholds. Pain. 2000;84:65-75.

7. Sullivan M, Bishop S, Pivik JT. The pain catastrophizing scale: development and validation. Psychol Assess. 1995;7:524-532.

8. Rivest K, Cote JN, Dumas JP, Sterling M, De Serres SJ. Relationships between pain thresholds, catastrophizing and gender in acute whiplash injury. Man Ther. 2010;15(2):154-159.

9. Keefe F, Lefebvre J, Maixner W, Salley A, Caldwell D. Self-efficacy for arthritis pain: relationship of thermal laboratory pain stimuli. Arthritis Care Res. 1997;10(3):177-184.

10. Bandura A. Self-Efficacy: The Exercise of Control. New York: W.H. Freeman and Company; 1997.

11. Dolce J, Doleys D, Raczynski J, Lossie J, Poole L, Smith M. The role of self-efficacy expectancies in the prediction of pain tolerance. Pain. 1986;27:261-272.

12. Vernon H, Mior S. The neck disability index: a study of reliability and validity. J Manipulative Physiol Ther. 1991;14:409-415.

13. Macdermid J, Walton D, Avery S, et al. Measurement properties of neck disability index: a systematic review. J Orthop Sports Phys Ther. 2009;39(5):400-417.

14. McHorney CA, Ware JE Jr, Raczek AE. The MOS 36-item short-form health survey (SF-36): II. Psychometric and clinical tests of validity in measuring physical and mental health constructs. Med Care. 1993;31(3):247-263.
15. McHorney CA, Ware JE Jr, Lu JF, Sherbourne CD. The MOS 36-item short-form health survey (SF-36): III. Tests of data quality, scaling assumptions, and reliability across diverse patient groups. Med Care. 1994;32(1):40-66.

16. Jensen M, Karoly P, Braver S. The measurement of clinical pain intensity: a comparison of six methods. Pain. 1986;27:117-126.

17. Jolliffea $C$, Nicholas $M$. Verbally reinforcing pain reports: an experimental test of the operant model of chronic pain. Pain. 2004; 107:167-175.

18. DiCiccio T, Efron B. Bootstrap confidence intervals (with discussion). Stat Sci. 1996;11:189-228.

19. Litt MD. Self-efficacy and perceived control: cognitive mediators of pain tolerance. J Pers Soc Psychol. 1988;54(1):149-160.

20. de Jong P, van Baast R, Arntz A, Merckelbach H. The placebo effect in pain reduction: the influence of conditioning experiences and response expectancies. Int J Behav Med. 1996;3(1):14-29.

21. Ashford S, Edmunds J, French D. What is the best way to change self-efficacy to promote lifestyle and recreational physical activity? A systematic review with meta-analysis. $\mathrm{Br} J$ Health Psychol. 2010;15:265-288.

22. Lee J, Napadow V, Park K. Pain and sensory detection threshold response to acupuncture is modulated by coping strategy and acupuncture sensation. BMC Complement Altern Med. 2014;14:324.

23. Kall LB. Psychological determinants of quality of life in patients with whiplash associated disorders-a prospective study. Disabil Rehabil. 2009;31(3):227-236.

24. Soderlund A, Denison E. Classification of patients with whiplash associated disorders (WAD): reliable and valid subgroups based on the multidimensional pain inventory (MPI-S). Eur J Pain. 2006;10(2):113-119.

25. Söderlund A, Lindberg P. Coping as a mediating factor between self-efficacy and disability in Whiplash associated disorders (WAD). J Whiplash Relat Disord. 2002;1(2):25-37.

26. Gustavsson C, Bergstrom J, Denison E, von Koch L. Predictive factors for disability outcome at twenty weeks and two years following a pain self-management group intervention in patients with persistent neck pain in primary health care. J Rehabil Med. 2013;45(2):170-176.
Journal of Pain Research

\section{Publish your work in this journal}

The Journal of Pain Research is an international, peer-reviewed, open access, online journal that welcomes laboratory and clinical findings in the fields of pain research and the prevention and management of pain. Original research, reviews, symposium reports, hypothesis formation and commentaries are all considered for publication.

\section{Dovepress}

The manuscript management system is completely online and includes a very quick and fair peer-review system, which is all easy to use. Visit http://www.dovepress.com/testimonials.php to read real quotes from published authors. 